http://jmscr.igmpublication.org/home/ ISSN (e)-2347-176x ISSN (p) 2455-0450

crossref DOI: https://dx.doi.org/10.18535/jmscr/v8i1.131

Journal Of Medical Science And Clinical Research

IGM Publication

An official Publication of IGM Publication

\title{
Assessment of Impact of Family Support on Practice of Child Survival Strategies: A Case Study of Mothers Attending Postnatal Clinic of a Southern Nigeria Primary Health Centre
}

\author{
Authors \\ Victory Edet Iyanam ${ }^{1 *}$, Alphonsus Udoh Idung ${ }^{1}$, Henry Effiong Jombo ${ }^{2}$ \\ Sunday Bassey Udoh ${ }^{1}$, Emem Akpanudo ${ }^{3}$ \\ ${ }^{1}$ Department of Family Medicine, ${ }^{2}$ Department of Psychiatry, ${ }^{3}$ Department of Paediatric Surgery, \\ Faculty of Clinical Sciences, College of Health Sciences, University of Uyo, Nigeria \\ *Corresponding Author \\ Dr Victory Iyanam \\ Department of Family Medicine, UNIUYO, Nigeria
}

\begin{abstract}
Background: The impact of family support on positive health practices and outcomes cannot be overemphasized especially in families with growing children.

Objective: The objective of this study was to assess the impact of family support on the practice of child survival strategies among mothers attending the postnatal clinic of a primary health care centre in southsouth Nigeria.
\end{abstract}

Methodology: This was a cross-sectional descriptive study involving 296 mothers who presented at the postnatal clinic of primary healthcare centre, Itu, South-South Nigeria between March and July, 2019 recruited through convenient sampling. A pre-tested intervener administered questionnaire was used to obtain information on socio-demographic characteristics of the mothers, practice of child survival strategies (CSS) and family support to practice CSS.

Result: The age of the respondents ranged from 15 -49 years, with mean and standard deviation of $28.18 \pm 7.07$ years. From the result obtained, greater percentage (87.5\%) of the mothers belonged to lower reproductive age (<35 years), had higher (secondary and tertiary) educational status (88.51\%), had lower income $(56.76 \%)$ and were of lower parity (88.51\%). Lower percentage of the mothers practiced most of the components of CSS as seen in 26.69\% (growth monitoring), $37.5 \%$ (oral rehydration therapy), $42.28 \%$ (complete childhood immunization) and $48.99 \%$ (environmental sanitation). However, majority of the respondents (79.05\%) who practiced CSS had support from family members; moreover $64.19 \%$ of them had adequate support, even though there was no significant statistical association between practice of CSS and family support.

Conclusion: The study has shown that even though the percentage of the mothers who practiced CSS was low in most of the components of CSS, most of the respondents who practiced CSS had adequate support from the family members. We recommend that information, education and counseling on the practice of CSS be made available not only to the mothers but also to other family members so as to ensure their involvement and adequate support to mothers in the practice of CSS, with the attendant benefits of averting child morbidity and mortality.

Keywords: Impact, family support, child survival strategies, mothers, south-south Nigeria. 


\section{Introduction}

Effective practice of child survival strategies have the potential of averting the menace of child morbidity and mortality, especially in the least developed countries with alarmingly negative indices of child well joining. ${ }^{1-4}$ This is because components of CSS including growth monitoring, oral rehydration therapy, breast feeding, childhood immunization, female education, family planning, food fortification, environmental sanitation, treatment of common injuries, health education, use of essential drugs to treat common childhood illnesses, and other child health promoting interventions and practices, have the potential to significantly reduce illnesses among children thereby enhancing their survival ${ }^{1,5,6,7}$.

The practice of child survival strategies among mothers, like all other health promoting programmes, is influenced by several factors including the age of mothers, maternal level of education, family level of income, socio-cultural influences, religion practices, marital status of mothers, availability of health facilities and other infrastructures and environmental factors 8,9-12 Furthermore and very importantly, studies have shown that the support rendered by family members make significant impact and contribute immensely in enhancing the practice of child survival strategies among mothers ${ }^{9,13-17}$ For instance women who receive adequate support from family members are physically assisted, financially empowered and emotionally stable to practice the relevant components of child survival strategies ${ }^{10,17-19}$ The opposite is the case with women with poor and inadequate support from family members. ${ }^{17}$ Several studies have affirmed the impact and influence of family on health of the members. ${ }^{20-22}$ The influence is expressed through various health practices among members including the practice of child survival strategies. This study therefore assesses the impact of family support on the practice of child survival strategies among mothers attending the postnatal clinic of a primary health centre in a South-South Nigeria setting.

\section{Methodology}

Study Area: This was a facility based study carried out at the postnatal clinic of primary health centre, West Itam, Itu, a suburban area of Akwa Ibom State, South-South Nigeria. The facility is one of the maternal and child health centres in the State and covers 10 settlements with a population of about 32,899 people. The postnatal clinic runs from $8 \mathrm{am}$ to $4 \mathrm{pm}$ daily from Monday to Friday, except on public holidays.

Study Design: This was a cross-sectional descriptive study involving 296 mothers who attended the postnatal clinic of the health centre for postnatal check up between March and July, 2019.

Sample Selection: A total of 296 mothers who presented at the facility during the period of the study were selected for the study, using the formula: ${ }^{23}$

$M=\frac{Z^{2} p(1-p)}{d^{2}}$

where,

$\mathrm{z}=$ confidence level at 95(standard rate of $1.96 \%$ ) at

$\mathrm{d}=5 \%$ acceptable margin of error (standard value at 0.05 )

$\mathrm{p}=$ prevalence of mothers with knowledge of child survival strategies ${ }^{6}$

Substitution in the above formula gives 296 ((in the nearest 10). A non-probability consecutive sampling technique was used to select the respondents. The inclusion criteria were all consenting mothers who attended the postnatal clinic during the period of the study. The exclusion criteria were non-consenting subjects as well as those postpartum women who were too ill.

Data Collection: A pretested semi-structured questionnaire was used to collect data from the respondents by the author and trained research assistants, after appropriate explanation of the purpose of the study was made, and verbal consent obtained from the respondents. The few respondents who had no formal education were assisted by the trained assistants in the use of local dialect. The data contained in the questionnaire 
include socio-demographic characteristics, practice of CSS and support of family members in the practice of CSS.

Data Analysis: Data from the study were analysed with SPSS version 22.0. The percentage of independent and dependent variabless were determined. Level of statistical significance was set at $\mathrm{p}<0.05$. Table were used to display data distribution as appropriate.

Ethical Consideration: Data for the study were collected based on the declaration of Helsinki. Verbal consent was obtained from the respondents. Permission was also obtained from the administrative head of the facility before commencement of the study.

\section{Results}

A total of 296 mothers were recruited for the study. Table 1 shows socio-demographic characteristics of the respondents. Greater percentage of the respondent $(87.50 \%)$ belonged to lower reproductive age ( $<35$ years), had higher (secondary and tertiary) educational status $(88.51 \%)$, were employed $(59.12 \%)$, had lower family income $(<\$ 50,000), 56.76 \%$ and were of lower parity (para $\leq 4), 88.51 \%$.

Table 2 shows the practice of CSS among the mothers. The proportion of mothers who practiced most of the components of CSS was low as seen in growth monitoring (26.69\%), oral rehydration therapy (37.30\%), exclusive breast feeding $(42.24 \%)$ and family planning (33.45\%). However, greater percentage of the mothers practiced few of the components of CSS such as food fortification $(54.05 \%)$, use of insecticide treated nets (ITN), $55.07 \%$ and prompt treatment of common injuries $(62.16 \%)$. Family support to practice CSS among the mothers is shown on table 3. Here, majority of the respondents (79.05\%) were supported to practice CSS by family members. Husbands supported most of the mothers to practice child survival strategies (79.39\%). Majority of the respondents (72.30\%) received financial support, $66.55 \%$ received physical support while $61.82 \%$ received emotional support. Greater percentage of the mothers $(64.19 \%)$ received adequate support while $14.19 \%$ received poor support. The association between family support and practice of child survival strategies is shown on table 4 . From the crosstabulation, greater percentage of mothers who practiced CSS had adequate support from family members while lower percentage of the respondents had inadequate support, even though no significant statistical association was found between the practice of CSS and family support.

Table 1a: Socio-demographic characteristics of the respondents

\begin{tabular}{lcc}
\hline Characteristic & Frequency $(\mathbf{n}=\mathbf{2 9 6})$ & Percentage $(\%)$ \\
\hline Age/Years & & \\
$15-24$ & 86 & 29.05 \\
$25-34$ & 173 & 58.45 \\
$35-44$ & 77 & 9.12 \\
$\geq 45$ & 10 & 3.38
\end{tabular}

\section{Residence}

Urban

Rural

\section{Educational Status}

No. Formal Education

Primary education 


\section{Currently Married:}

Yes

89.53

No

10.47

Occupation:

Unemployed

40.88

Civic servant

Trading

Farming

Artisan

Family Income Level (

$10,000-49,000$

Table 1b: Socio-demographic characteristics of the mother

\begin{tabular}{lcc}
\hline Characteristic & Frequency $(\mathbf{n = 2 9 6})$ & Percentage $\mathbf{( \% )}$ \\
\hline Ethnics Group: & & \\
Ibibio/Annang/Oron & 184 & 62.16 \\
Efik & 48 & 16.22 \\
Igbo & 15 & 5.07 \\
Yoruba & 11 & 3.72 \\
Hausa/Fulani & 30 & 10.13 \\
Other (Unspecified) & & \\
Ethnic Group & 8 & 2.70 \\
Religion: & & \\
Christianity & 2.63 & 88.85 \\
Islam & 33 & 11.15 \\
Parity: & & \\
1-2 & 167 & 56.42 \\
3-4 & 95 & 32.09 \\
$\geq 5$ & 34 & 11.49 \\
\hline
\end{tabular}

Table 2: Practice of child survival strategies (CSS)

$\begin{array}{lcc}\text { Characteristic } & \text { Frequency }(\mathbf{n = 2 9 6}) & \text { Percentage }(\%) \\ \text { CSS practiced: } & 79 & 26.69 \\ \text { Growth monitoring } & 111 & 37.50 \\ \text { ORT } & 128 & 42.24 \\ \text { Exclusive breastfeeding } & 137 & 46.28 \\ \text { Complete immunization } & 99 & 33.45 \\ \text { Family planning } & 160 & 54.05 \\ \text { Food fortification with iodine } & & \\ \text { multivitatimins } & 102 & 34.46 \\ \text { Supplementation } & 126 & 42.57 \\ \text { Use of essential drugs } & 145 & 48.99 \\ \text { Environmental sanitation } & 105 & 35.47 \\ \text { De-worming } & & \\ \text { Use of insecticide } & 163 & 55.07 \\ \text { Treated net (ITN) } & & \end{array}$


Prompt treatment of

Common injuries

62.16

Other prevention and

Prompt treatment of

Malaria

111

37.50

Table 3: Family support to practice child survival strategies among the respondents

\begin{tabular}{|c|c|c|}
\hline Characteristic & Frequency $(n=296)$ & Percentage $(c$ \\
\hline \multicolumn{3}{|c|}{$\begin{array}{l}\text { Support from the } \\
\text { family to practices CSS: }\end{array}$} \\
\hline Yes & 234 & 79.05 \\
\hline No & 62 & 20.95 \\
\hline \multicolumn{3}{|c|}{ Family members involved in } \\
\hline \multicolumn{3}{|c|}{ Support to practice of CSS: } \\
\hline Husbands & 238 & 79.39 \\
\hline Inlaws & 112 & 37.84 \\
\hline Siblings & 99 & 33.45 \\
\hline Parents & 170 & 57.43 \\
\hline \multicolumn{3}{|l|}{ Nature of support ${ }^{* *}$} \\
\hline Financial & 214 & 72.30 \\
\hline Physical & 197 & 66.55 \\
\hline Emotional & 183 & 61.82 \\
\hline \multicolumn{3}{|l|}{ Level of support ${ }^{* * * *}$} \\
\hline Adequate & 190 & 64.19 \\
\hline Inadequate & 64 & 21.62 \\
\hline Poor & 42 & 14.19 \\
\hline
\end{tabular}

*Some respondents got support from more than one source.

**Financial support: Getting financial assistance to pay for items related to child's well being.

Physical support: Assisting in caring for the child including movement to the health facility.

Emotional support: Showing love, compassion, care, empathy towards the care of the child; being around, asking questions and listening to concerns expressed towards the care of the child.

***Adequate support: Physical, financial and emotional support (3-level support)

Inadequate support: Either financial and physical support only, financial and emotional support only or physical and emotional support only (2-level support)

Poor support: Either financial support only, physical support only or emotional suppot only (1-level support)

Table 4: Association between family support and practice of CSS

$\begin{array}{llc}\text { Characteristics } & \text { Practice of CSS } & \text { Test } \\ & \text { Yes N(\%) No N(\%) } & \text { Statistics }\end{array}$

Family support:

Adequate

Inadequate

Family support:

Adequate

Inadequate
Growth monitoring

51(64.56) 139 (64.05)

28(35.44) 78(35.95)

Oral Rehydration Therapy

71(63.96) 119(64.32)

40(36.04) 66(36.68)
$X^{2}=0.006$

Df 1

$$
\mathrm{P}=0.937
$$

$X^{2}=0.004$

Df 1

$$
\mathrm{P}=0.950
$$


Family support:

Adequate

Inadequate

Family support:

Adequate

Inadequate

Family support:

Adequate

Inadequate

Family support:

Adequate

Inadequate

Family support:

Adequate

Inadequate

Family support:

Adequate

Inadequate

\section{Exclusive Breastfeeding}

82(64.06) 108(64.29)

46(35.94) 60(35.71)

Complete Immunization

88(64.23) 102(64.15)

49(37.77) 57(35.85)

Family Planning

64(64.65) 126(63.96)

35(35.35) 71(36.04)

Environmental Sanitation

93(64.14) 97(64.24)

52(35.86) 54(35.76)

Prevention and Treatment of common injuries

118(64.13) 72(62.29)

66(35/97) $40(35.71)$
$X^{2}=0.004$

Df 1

$$
\mathrm{P}=0.968
$$

$X^{2}=0.002$

Df 1

$$
\mathrm{P}=0.988
$$

$X^{2}=0.014$

Df 1

$$
\mathrm{P}=0.907
$$

$X^{2}=0.003$

Df 1

$$
\mathrm{P}=0.986
$$

$X^{2}=0.001$

Df 1

$$
\mathrm{P}=0.978
$$

Prevention and prompt treatment Of malaria

109(64.12) 81(64.80)

$\mathrm{X}^{2}=0.001$

61(35.88) 45(35.20)

Df 1

$\mathrm{P}=0.976$

*Inadequate suppor $=$ inadequate and poor support.

\section{Discussion}

The study has shown that the average percentage of mothers who practiced all the components of child survival strategies at the primary health centre, Itu South-south Nigeria was low (42.80\%). This value was however higher than the finding by Abimbola, et al, ${ }^{6}$ in a study done among mothers in a local setting in Western Nigeria but lower than findings made by Sanusi, et al in a study done among nursing mothers and their children in a well baby clinic in Ibadan, Nigeria. ${ }^{24}$ The lower percentage of mothers who practiced CSS in this study and the study by Abimbola, et al could be due to the location of the study which were all local communities, compared to the study by Sanusi, et al which was carried out in an urban centre of Ibadan, Nigeria. Also most of the respondents in this study were of lower average monthly family income. This could have contributed to the lower percentage of mothers who practiced most of the components of CSS in the study. The place of improved socio-economic conditions in health quality, practices and outcomes cannot be overemphasized. ${ }^{25-27}$ This strongly underscores the importance of improving the socioeconomic status of rural and suburban communities dwellers through relevant policies and programmes, with the aim of improving their health preventive practices including the practice of CSS.

The study has also shown that majority of the mothers who practiced CSS did not just have 
support from family members but had adequate support (physical, emotional and financial support 3 level support) compared to the minority who had inadequate (2-level support) and poor (1level) supports respectively. This findings agree with findings from several other studies on the impact of family support on health practices globally. ${ }^{13-16-20-22}$ Also that husbands were the most supportive of the family members to the women in the practice of CSS is not surprising considering the fact husbands are the closest persons to the respondents. These re-emphasize the need to direct information, education and communication on CSS not only to the mothers but also to other family members, especially close family members, so as to draw their support to the young mothers with the aim of enhancing the practice of CSS so as to avert morbidity and mortality among children thus enhancing their survival.

\section{Conclusion}

The study has shown that greater percentage of mothers who practiced CSS in primary Health Centre, Itu, a sub-urban area of south-south Nigeria had adequate support from family members, even though the percentage of the mothers who practiced all the components of CSS was low. We recommend that information, education and counselling on the practice of CSS should be directed not only to the mothers but also to other family members so as to draw adequate support to the young mothers in the practice of CSS , with the attendant benefit of averting child morbidity and mortality.

Conflict of interest: There is no conflict of interest among the authors

Funding: The funding of this article is borne purely by the authors.

Acknowledgement: We acknowledge and commend the support given to us by the management and staff of PHC, West-Itam, Itu towards the success of this work.

\section{References}

1. Cescar C. Improving maternal and child health in northern Nigeria. Available: @:https://www.theepochtives.com/improvin g_maternal_and_child_health_in_northern_ nigeria. Accessed in: 22/5/2019.

2. Mulholland EK, Smith L, Carneiro I, Becker H, Lehmam D. Equity and child survival strategies. Bulletin of the World Health Organisation. Available @: http://www.who.int. Assessed on 10/05/2019.

3. UNICEF. Child Health and Community Health Systems. Available @:http://www/unicef.org/health/indeaquate _childsurvival.,htw. Accessed on 26/5/2019.

4. UNICEF DATA. Under 5 Morbidity Available@:htt//dataunicef.org/topic./childs urvial/underfine. accessed on 28/5/2019.

5. Bako ZA. The implementation of government policy on child survival strategies in Ardo-Kola local government area of Taraba State of Nigeria. available@:http://kubanni.abu.edu.ms/jspui. bits. Accessed on 28/5/2019.

6. Abimbola SA, Adebukola OC, Samuel AO: knowledge and practice of mothers on child survival strategies in Odela local government area, Ogun State, Nigeria.

7. Bhutta ZA. Integrated strategies to address maternal and child health and survival in low income settings: Implication for Haiti. Perm J 2016; 20(2): 94-95.

8. Quansah E, Oheme LA, Nonal L, Mireke MO, Karika TK. Social factors influencing child health in Ghana. Plos ONE 2016; 11(1): e0145401.doi:10.1371.

9. Azu DE, Chinedu S, Samuel OW, Azuh A, Joshua G, Amoo EO. Factors influencing the survival of under five children among women visiting health care facility in semiurban communities in Nigeria . Cogent Arts and Humanities 2019; 6:1, Doi:10. 1080/23311983. 2019. 1686800. 
10. Jegede AS, Owumi BE, Factors influencing infant immunization uptake in the Yoruba Community of South Western Nigeria. J Common Med Health Edu 2013; 3:215.

11. Radamouch O, Cedomir S, Alexander V, Tasic A, Mavkovic R. The influence of education on family planning. Med Biol 2006; 13(1); 58-64.

12. Anyanwu JI, Ezegbe BN, Eskay A. Family planning in Nigeria: A myth or reality? Implication for education. J Edu Pract 2013; 4(12): 26-28.

13. Thomas PA, Liu H, Umberson D. Family relationships and well-being. Innov Ageing 2017; 1(3): 1gxo25.

14. Social and economic factors. Family and social support. Available @:www.countryhealthrunkings.org.

Accessed on 12/12/2019.

15. Rebin M, Uchino BN. Social and emotional support and its implication for health. Curr Opin Psychiatr 2008; 2(2): 201-205.

16. Prazeres F, Sartiago L. Relationship between health related quality of life, perceived family support and imminent health needs in adult patients with multi morbidity attending primary care in Portugal: a multi centre cross-sectional study. Health and Quality of Life Outcome 2016; 156 (2016): 4.

17. UNITE FOR SIGHT. Family dynamics and Health. Available @ www.unitsforsignit.org/gender_power.

Accessed on: 12/12/2019.

18. Samandari G, Speizer SI, O'cornel K. The role of social support and parity in contraceptive use in Cambodia. Int Perspect Sexual Reprod Health 2010; 36(3): 48-66.
19. WHO. Family as centre of health development. Report of the regional meeting, Barkor, Thanland 2013.

20. Campel TH, Brany JH. The family influence on health. In: Rakel RE (ed) Textbook of family practice, $9^{\text {th }}$ edition. WB Saunders Company, Philadelphia 2009;31.

21. Colle-kelly K, Seaborn DB. How Families affect illness; Research on families influence on health. In: Sloane PD, Slatt LM, Ebel MH, Smith MA, Power D, Viera $\mathrm{AJ}(\mathrm{Ed})$. Essential of Family Medicine. $6^{\text {th }}$ Edition. Lippincott Willians and Wikins, NY 2002;362.

22. Bigombe B, Khadagha GM. Major trends affecting families in sub-Sahara. Africa. United nations DESA family and social development population 2003.

23. US department of Health and Human Services. Calculating sample size. Available @:www.whs.gov. Accessed on 25/5/2019.

24. Sanusi RA, Gbadamosi AO DO Mothers' knowledge and practice of child survival strategies affect the nutritional status of their children? Pak J Nutr 2009; 8(9): 1506-1511

25. Lenhart $O$. The effects of income on health: new evidence from the earned income tax credit. Rev Econ Household 2019; 17(2): 377-400.

26. Wolf SH, Aron L, Simon SM, Zimmerman E. How are income and Wealth linked to health and longevity. Centre on Society and Health. Available @: http//www.healthaffairs. org $>$ doi $>$ full. Accessed on 25/5/2019.

27. Marmot M. The influence of Income on health: Views of an epidemiologist. Health Affairs 2002. Available @: www.healthaffairs.org. accessed on 28/5/2019. 